\title{
Morphology and Filterability of Red Blood Cells in Neonatal and Adult Rats
}

\author{
K. GUNNAR ENGSTRÖM AND LARS OHLSSON \\ Department of Histology and Cell Biology, University of Umeå, S-901 87 Umeå, Sweden
}

\begin{abstract}
Red blood cell (RBC) deformability in rats of various ages was assessed by filtration ( $3 \mu \mathrm{m}$ Nuclepore membranes). Neonatal rat RBC (1 d old) had lower filterability, both in terms of $R B C$ incremental volume $(9.97 \pm$ 1.85 versus $0.33 \pm 0.28 \mathrm{~nL}$ at $180 \mathrm{~d}$ of age, mean $\pm \mathrm{SD}, p$ $<0.001)$ and the number of filter clogging particles $(25.7$ \pm 3.1 versus $\left.18.9 \pm 3.4 \mathrm{RBC} \times 10^{3} / \mathrm{s}, p<0.001\right)$. The lower filterability correlated with a larger $\mathrm{RBC}$ volume $\left(169 \pm 12.6\right.$ versus $\left.69 \pm 3.2 \mu \mathrm{m}^{3}, p<0.001\right)$ and with a wider minimum cylindrical diameter $(3.87 \pm 0.15$ versus $2.84 \pm 0.05 \mu \mathrm{m}, p<0.001)$. Almost all of the neonatal $\mathrm{RBC}$ had a minimum cylindrical diameter exceeding the 3 $\mu \mathrm{m}$ nominal pore size of the filters. The calculated resistance to initial folding was also significantly greater, as indicated by a static bending analysis of initial deformation. However, when the larger size of neonatal RBC was taken into consideration, and thus their greater projected area on which forces are applied, they appear to be at least as deformable as the adult type RBC. This finding may explain the contradiction between RBC filtration experiments and other approaches based on RBC deformations in shear flow, which have been unable to detect a hampered flexibility of neonatal RBC. In view of the more pronounced differences between neonatal and adult $R B C$ in rats than in human subjects, the rat is an interesting model for studying this physiologic phenomenon in newborns. (Pediatr Res 27: 220-226, 1990)
\end{abstract}

\section{Abbreviations}

MCD, minimum cylindrical diameter MCH, mean corpuscular hemoglobin

MCHC, mean corpuscular hemoglobin concentration

MCV, mean corpuscular volume

RBC, red blood cell

RBCiv, red blood cell incremental volume

WBC, white blood cell

SAI, surface area index

SWI, swelling index

Human neonatal RBC are less filterable compared with adult $\mathrm{RBC}$ (1). The filterability is also known to be lower in preterm than in term neonates (2). The diminished ability to pass through narrow pores may cause sequestration and shorter life span of neonatal $\operatorname{RBC}(3,4)$ and may also contribute to serious circulatory dysfunctions, e.g. congestive heart failure, respiratory dis-

Received May 8, 1989; accepted October 5, 1989.

Correspondence and reprint requests K. Gunnar Engström, Department of Histology and Cell Biology, University of Umeå, S-901 87, Umeå, Sweden.

Supported by the Swedish Medical Research Council (12x-2288), the Swedish Diabetes Association, Swedish Hoechst AB, the Groschinsky Foundation, and the Svensson Foundation. tress, cyanosis, cerebral infarction, and necrotizing enterocolitis (5-9).

$\mathrm{RBC}$ deformability is one of the major determinants of blood rheology and is influenced by 1) cellular shape, of which the area-to-vol ratio is usually emphasized, 2) cytoplasmic and membrane viscosity, and 3) RBC aggregation. In neonates, $\mathrm{RBC}$ are generally large with a decrease in membrane area-to-vol ratio (10), which is the most likely explanation for their greater resistance to pore transit when assessed by filtration or micropipette aspiration $(1,2,11)$. However, neither cytoplasmic viscosity nor membrane mechanical properties differ notably between neonatal and adult $\operatorname{RBC}(11,12)$.

Viscometry, rheoscopic measurements (4), and ektacytometry (13) have, in contrast to filtration experiments, shown no differences in deformability between neonatal and adult RBC. Filterability measurements are more sensitive to RBC shape than cytoplasmic viscosity or membrane rigidity, which is thought to explain the discrepancy between this and the other approaches more specifically reflecting cell viscosity. In the microcirculation, however, capillary diameters may be significantly smaller than the diameters of the RBC. In fact, the thinnest capillaries appear to be very close to the limit of deformation of circulating $\mathrm{RBC}$ (14). This encourages the use of filtration in assessing RBC deformability.

In view of the necessity of $\mathrm{RBC}$ flexibility, the lesser ability of neonatal $\mathrm{RBC}$ to deform needs further investigation to explore the mechanisms behind circulatory dysfunctions in the newborn. So far, all studies have concerned human RBC. In our study, rats of ages from 1 to $180 \mathrm{~d}$ were analyzed. RBC deformability was measured by a filtration technique making it possible to evaluate both the pore transit resistance and the proportion of filter clogging cells. Cross-sections of individual RBC were measured and deformability expressed in terms of area-to-vol ratio, SAI (the relative excess of membrane area beyond that required to enclose the cellular volume), and SWI (the relative swelling to become a sphere of same membrane area), MCD (the smallest possible diameter of a tube-shaped RBC), but also by means of a static bending analysis of initial folding (15-18).

\section{MATERIALS AND METHODS}

Animals. Female Sprague-Dawley rats were purchased from Alab Laboratories AB (Stockholm, Sweden). Three different age groups were used. Neonatal rats were obtained together with their mothers within $24 \mathrm{~h}$ from delivery. One rat from each of six litters was cardiopunctured at 1,10 , and $20 \mathrm{~d}$ of age. One group of six rats was studied at 40 and $70 \mathrm{~d}$. Another group of six rats was followed between 100 and $180 \mathrm{~d}$ of age. Rats were kept under controlled conditions of constant temperature (22$24^{\circ} \mathrm{C}$ ), humidity (55-65\%), and illumination from 0600 to 1800 h.

Blood sampling. Neonatal and young rats (1-20 d of age) were anaesthetized using intraperitoneal pentobarbital, $100 \mathrm{mg} / \mathrm{kg}$. Blood was obtained from the right heart ventricle by means of a mouth-operated collecting tube, in which EDTA had been added 
as a solid to give a final concentration of approximately $5 \mathrm{mmol} /$ $\mathrm{L}$ whole blood. Whole blood, $44.7 \mu \mathrm{L}$, for electronic measurements, was aspirated into a calibrated pipette and suspended in $10 \mathrm{~mL}$ Isotone II medium (Unopette microcollection system, Becton Dickinson, Rutherford, NJ). Another $5 \mu \mathrm{L}$ of blood were diluted in $1 \mathrm{~mL}$ RBC suspension media for morphologic examinations, whereas the rest was aspirated into a thin, $12-\mathrm{cm}$ long polyethylene capillary tube (code 19-0040-01, Pharmacia, Uppsala, Sweden). The capillary tube was sealed at one end by gently heating it over a flame. Each batch of tubes had been carefully calibrated by weighing the water contained by a certain length. The variability in displacement within each batch is negligible (19). The tubes with blood were centrifuged at $1500 \times g$ for 15 $\min \left(4^{\circ} \mathrm{C}\right)$ supported by a rigid holder. The microhematocrit was recorded and a length corresponding to $25.0 \mu \mathrm{L}$ of packed $\mathrm{RBC}$ was cut from the mid-section of the RBC column and suspended in $50 \mathrm{~mL}$ of buffer to yield a hematocrit of $0.05 \%$.

In adult, unanesthetized rats (40-180 d of age), blood was obtained from the tail tip. After a few min warming of the tail with an infrared lamp, vessels dilated and blood was easily sampled. Blood was collected into microfuge tubes, which contained EDTA, and was processed as explained above.

$\mathrm{RBC}$ was incubated at a low concentration of bovine serum albumin at room temperature for $1 \mathrm{~h}$ before filtration and morphologic measurements, to minimize stomatocytic shape transformation (Engström KG, Täljedal I-B, unpublished data).

$R B C$ suspension media. The $\mathrm{RBC}$ suspension media was a Hepes-buffered Krebs-Ringer solution of a calculated 300 mos$\mathrm{mol} / \mathrm{L}$ supplemented with $0.2 \mathrm{~g} / \mathrm{L}$ BSA (fraction $\mathrm{V}$, Pentex, Miles Scientific, Naperville, IL) and $5 \mathrm{mmol} / \mathrm{L}$ glucose. The $\mathrm{pH}$ was adjusted to 7.40 using $\mathrm{NaOH}$. The medium was prefiltered through $0.8 \mu \mathrm{m}$ Nuclepore membranes before use.

$R B C$ and $W B C$ counting. In whole blood, the $\mathrm{RBC}$ count, $\mathrm{Hb}$, $\mathrm{MCV}, \mathrm{MCH}, \mathrm{MCHC}$, WBC count, and platelet count were measured by means of a Coulter counter (Model S-plus, Coulter Electronics, Inc., Hialeah, FL). The concentration of resuspended $\mathrm{RBC}$ used for filtration experiments, as well as the occurrence of nucleated cells in suspension, were measured in a counting chamber by light microscopy. Nucleated cells were stained with Türks reagent $(0.02 \%$ gentianviolet $\mathrm{B}$ in a $6.2 \%$ acetic acid solution).

Measurements of $R B C$ morphology. A special measuring chamber for RBC morphology was made from cover-slips on a microscope slide. Into a rectangular compartment, measuring approximately $18 \times 10 \times 0.17 \mathrm{~mm}$, a drop of suspended RBC was introduced and the openings sealed with immersion oil. RBC were allowed to sediment with the chamber held upside down. After $2 \mathrm{~min}$, the chamber was turned right side up and mounted in the microscope. A large proportion of the previously settled $\mathrm{RBC}$ were then hanging from the upper glass surface. The RBC diametrical cross-sections were focused on using bright field illumination (Carl Zeiss $\times 100 / 1.25$ oil objective lens, Oberkochen, FRG). A digitizing table with light-spot cursor (MOPVideoplan, Kontron Bildanalyse GmbH, Munich, FRG) was optically superimposed on the microscopic image, and the RBC diameter (D), maximum toroidal thickness (T), and central thickness $(\mathrm{C})$ were measured. A thin diffraction band surrounded the $\mathrm{RBC}$ cross-sectional profile due to differences in refractive indices between RBC and medium. The uniform shell rule was therefore applied during measurements (20). The method is consistent with that described in detail in a previous publication (17).

$R B C$ profile calculations. The $\mathrm{RBC}$ measurements $(\mathrm{D}, \mathrm{T}$, and $C)$ were used to compute the membrane area and volume with an equation expressing the RBC cross sectional curvature (17, 18). MCD, SAI, and SWI are derived from area and volume according to:

$$
\begin{gathered}
0=-\pi(M C D)^{3} / 12+A(M C D) / 4-V \\
S A I=0.207 A V^{-2 / 3} \\
S W I=0.094 A^{3 / 2} V^{-1}
\end{gathered}
$$

Calculations of $R B C$ bending mechanics. It is possible to express mathematically the mechanical resistance to initial bending deformation of the RBC corpuscle by means of a section modulus value. The section modulus only considers the RBC shape and size and not the membrane mechanical properties as such, e.g. elastic shear, dilation, or bending moduli, or their interrelations. The section modulus refers to the entire RBC corpuscle, built up by a $0.01-\mu \mathrm{m}$ thick membrane shell with linearly elastic behavior (21).

The corpuscle section modulus is further analyzed by means of a static bending model, in which the RBC is stressed by a pressure difference between the two sides of the cell (here set to a fictitious pressure of $1 \mathrm{kPa}$ ). The pressure load builds up a bending moment and hence membrane tensions, both having maxima at the $\mathrm{RBC}$ diametrical cross-section. The diametrical cross-section is therefore crucial for the initiation of deformation and is calculated as representative for the whole corpuscle (15, 18). The higher the tension, the more deformable is the RBC. The tension is calculated by division of bending moment with section modulus. This method of theoretical analysis may be valuable in evaluating the influence of size and shape only on the RBC deformability (15-18).

Measurements of $R B C$ filterability. RBC suspensions were filtered through 3- $\mu \mathrm{m}$ pore size Nuclepore polycarbonate membranes (diameter $13 \mathrm{~mm}$, lot 62 EO B25 or 62 A5 C30 with an average pore density of $1.81 \times 10^{6}$ pores $/ \mathrm{cm}^{2}$ ) driven by a constant hydrostatic pressure of $600 \mathrm{~Pa}$. The filtration rate was measured by collecting the filtrate on a digital balance (Sartorius 3716, Sartorius Werke GmbH, Göttingen, FRG) and the weight recorded every $5 \mathrm{~s}$ during a 1 -min filtration period. Before $\mathrm{RBC}$ filtration, each filter was calibrated by measuring the filtration rate for cell-free medium.

The ability of RBC to pass the filter pores was evaluated using a regression analysis of the filtration rate. The starting point of regression was taken to be $10 \mathrm{~s}$, at which time all pores of the membrane were interacting with $\mathrm{RBC}$ as calculated from the average $\mathrm{RBC}$ particle concentration and the number of pores. At that time, $10 \mathrm{~s}$, the filtration rate was stable and declined linearly owing to filter clogging by rigid $\mathrm{RBC}$. To obtain the initial $\mathrm{RBC}$ filtration rate (FRBC) the regression line was extrapolated to $10 \mathrm{~s}$ in real time of the 60 -s filtration period. The RBCiv was then calculated as:

$$
R B C_{i v}=\left(F_{m} / F_{R B C}-1\right) / R B C_{\text {count }}
$$

This equation expresses the relative decrease in filtration rate due to $\mathrm{RBC}$ compared with the filtration rate of medium alone (Fm) and with respect to the concentration of $\mathrm{RBC}$ in the suspension (RBC count). Mathematically, the RBC incremental volume $(\mathrm{L} / \mathrm{RBC})$ is the volume of medium that is hindered from passing a narrow pore owing to the presence of an $\mathrm{RBC}$ within it.

The flow rate declines with time of filtration because of clogging particles $(\mathrm{CP})$. These particles can be evaluated by relating the slope, $\mathrm{k}$ (filtration rate as a function of filtration time), and the average number of filterable pores $\left(\mathrm{Np}, 1.15 \times 10^{6}\right.$ pores $)$ to the initial filtration rate, FRBC.

$$
C P=N_{p} k / F R B C
$$

The clogging particles reflect the frequency with which filter pores are plugged $(\mathrm{RBC} / \mathrm{s})$. The present calculations are in accordance with those described by Matrai et al. (22), except that filtration rate is here made a function of time instead of volume.

Statistical analyses. Results are given as mean values \pm SD. Unpaired Student's $t$ test was used to evaluate differences between neonatal ( $1 \mathrm{~d}$ old $)$ and adult rats ( $180 \mathrm{~d}$ old, if not otherwise stated). Correction was made for unequal variance between groups. 


\section{RESULTS}

Body wt gain declined from an average of $1.65 \mathrm{~g} / \mathrm{d}$ in the neonatal period (d 1 to 10 ) to $0.54 \mathrm{~g} / \mathrm{d}$ in the adult (d 100 to 181). At $181 \mathrm{~d}$ of age body wt was close to $300 \mathrm{~g}$.

In Figure $1 a-f$, the micro-hematocrit, electronically measured whole blood $\mathrm{Hb}, \mathrm{RBC}$ count, $\mathrm{MCV}, \mathrm{MCH}$, and $\mathrm{MCHC}$ are shown. The micro-hematocrit and hemoglobin in neonatal rats were not significantly different from those in the adult, but showed distinct minima around d $20(p<0.001$ versus $\mathrm{d} 1$ or 40). The RBC count increased successively and reached the adult level at $70 \mathrm{~d}$ of age $(p<0.001$ versus $\mathrm{d} 1)$, whereas the MCV showed a pronounced decrease from the neonatal $(142 \pm 7.83$ $\left.\mu \mathrm{m}^{3}\right)$ to the adult period $\left(56.6 \pm 1.59 \mu \mathrm{m}^{3}\right.$ between 20 and 180 $\mathrm{d}, p<0.001)$. The MCH decreased $(p<0.001)$ in parallel with the $\mathrm{MCV}$ owing to a relatively constant $\mathrm{MCHC}$.

In $10 \mathrm{~d}$ the platelet count increased from $468 \pm 53 \times 10^{9} / \mathrm{L}$ in the $1-\mathrm{d}$ old rat to the adult level of $843 \pm 130 \times 10^{9} / \mathrm{L}$. WBC decreased steeply to approximately half of the concentration in neonates. However, this Coulter measurement is likely also to include nucleated $\mathrm{RBC}$, which were found to constitute $54 \pm$ $6.8 \%$ of the total number of nucleated cells at $1 \mathrm{~d}$ of age. At 10 and $100 \mathrm{~d}$ of age, the fraction was $0.91 \pm 0.64$ or $0.21 \pm 0.33 \%$, respectively. The recalculated true WBC count does not vary notably with age and is on the order of $8 \times 10^{9} / \mathrm{L}$. On d 1, $96 \pm$ $1.6 \%$ of the total number of nucleated cells were nucleated RBC in the $\mathrm{RBC}$ filtration suspension, a figure that fell to $2.2 \pm 1.9 \%$ within $10 \mathrm{~d}$. The relative proportion of nucleated $\mathrm{RBC}$ to the total number of RBC in the resuspension was about $0.05 \%$ in the 1 -d-old rat and $0.00014 \%$ in the adult rat.

The measured diameter, toroidal (maximum) thickness, and central (minimum) thickness, calculated membrane area, and $\mathrm{RBC}$ volume are shown in Figure $2 a-e$. The RBC size decreased significantly $(p<0.001)$ to the adult levels, by $20 \mathrm{~d}$ for toroidal thickness, and by $70 \mathrm{~d}$ for diameter, membrane area, and volume. Central thickness showed a minimum at $20 \mathrm{~d}$ of age $(p<0.001$ a)

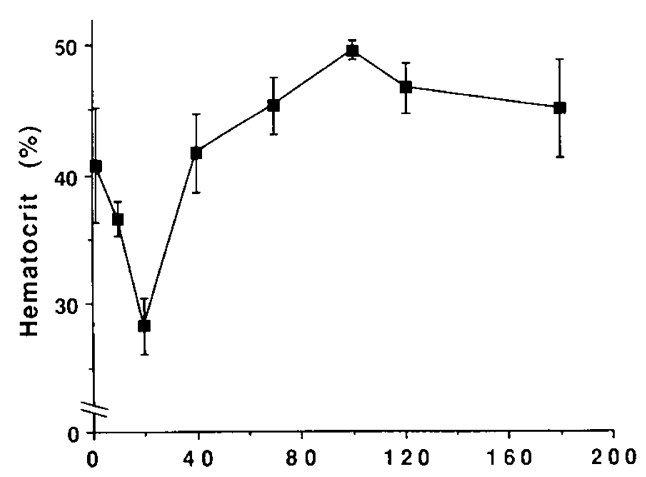

c)

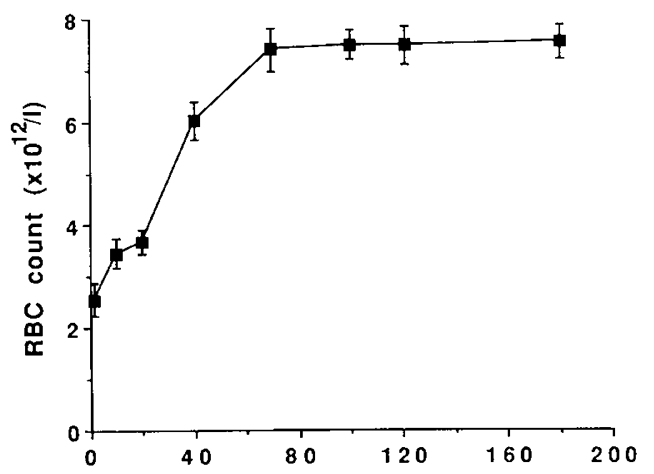

e)

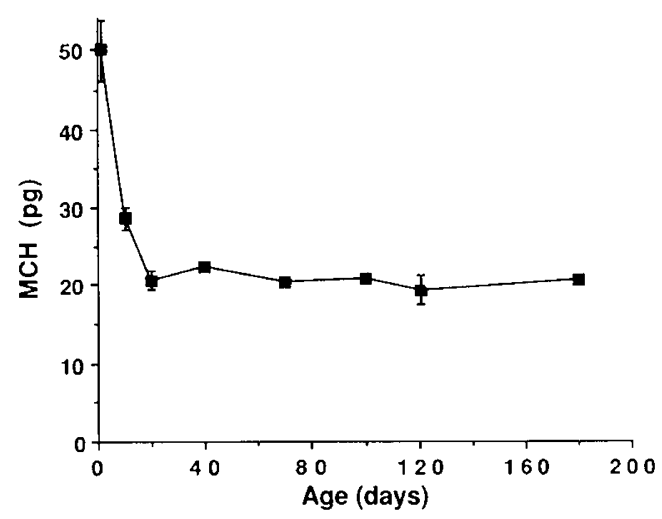

b)

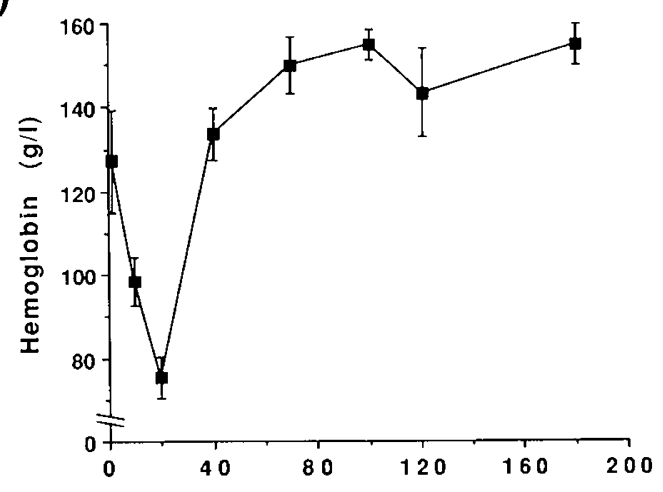

d)

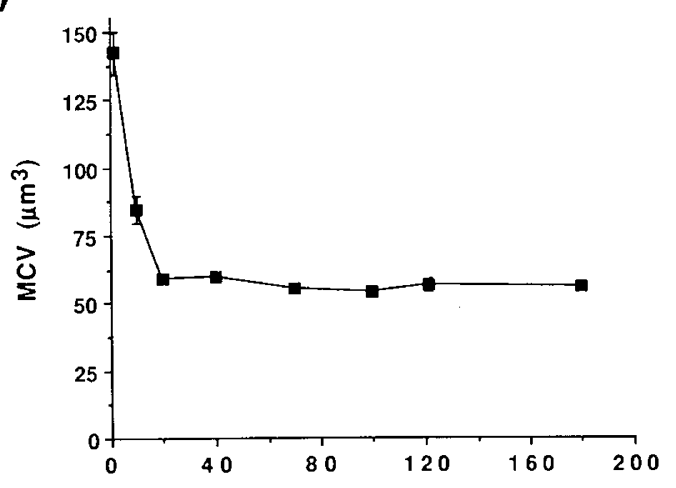

f)

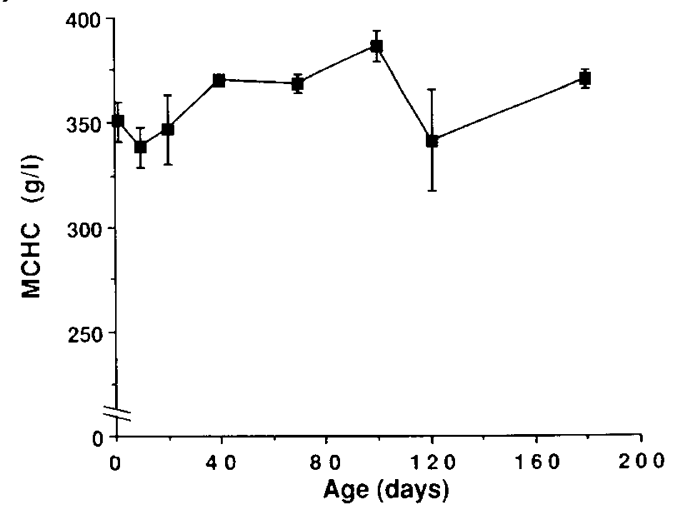

Fig. 1. $a$, micro-hematocrit; $b$, electronically determined $\mathrm{Hb}$ concentration; $c, \mathrm{RBC}$ count; $d, \mathrm{MCV} ; e, \mathrm{MCH}$; and $f$, $\mathrm{MCHC}$ as a function of age. Mean \pm SD in three groups of six rats each (1-20,40-70, and 100-180 d of age). 
a)

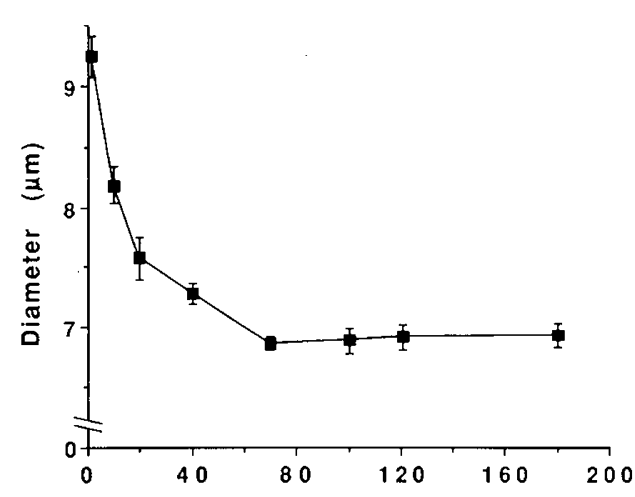

c)

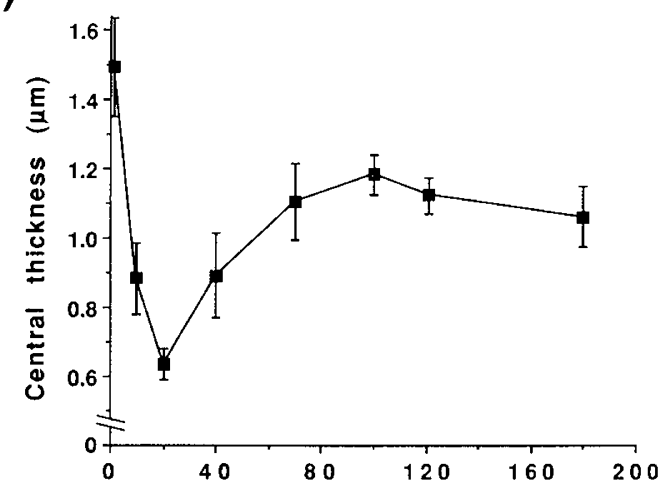

e)

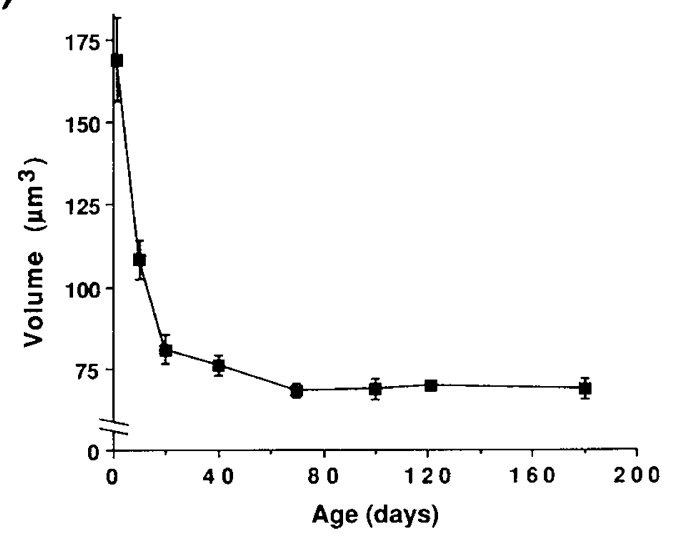

b)

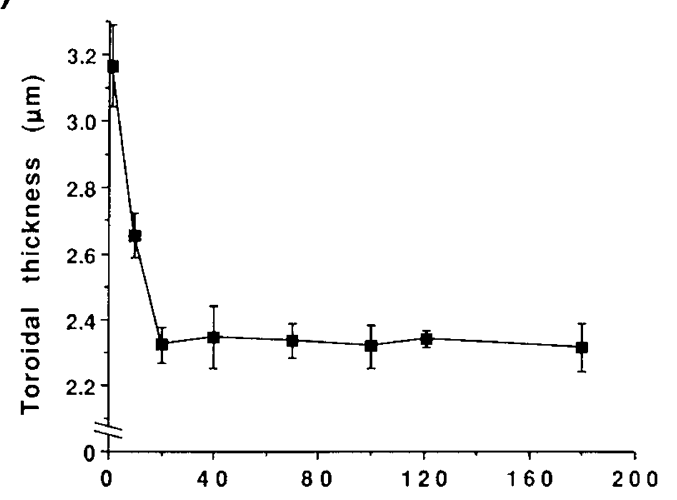

d)

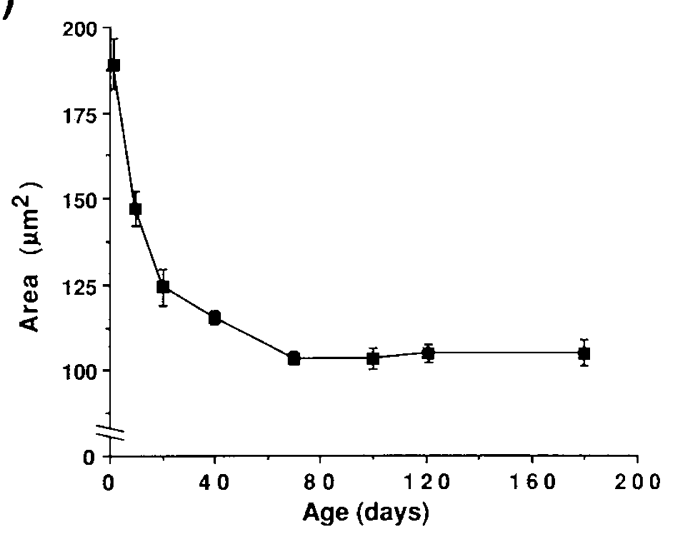

Fig. 2. $a$, measured RBC diameter; $b$, toroidal thickness; $c$, central thickness; $d$, calculated membrane area; and $e$, volume as a function of age. Mean \pm SD in three groups of six rats each (1-20, 40-70, and 100-180 d of age).

versus $\mathrm{d} 1$ and 180 ) and then increased in the adult rat to a level about $75 \%$ less than $(p<0.001)$ that seen in the neonates.

Figure $3 a-f$ show the deformability indices. These parameters were calculated from the morphologic measurements in Figure $2 a-c$. The area-to-vol ratio increased about $40 \%(p<0.001)$ between 1 and $20 \mathrm{~d}$ of age to the adult level. SAI showed a corresponding increase $(p<0.001)$ between 1 and $20 \mathrm{~d}$ of age but then regained the neonatal level within $70 \mathrm{~d}$. An almost identical curve was seen for the SWI (not shown). The proportion of RBC exceeding $3 \mu \mathrm{m}$ in MCD, and section modulus, the calculated $\mathrm{RBC}$ resistance to deformation, decreased to a minimum at $20 \mathrm{~d}$. However, the RBC membrane tension indicated a greater deformability for neonatal and young $\mathrm{RBC}$, with a maximum at $20 \mathrm{~d}$ of age, but then a fall to the adult and less deformable level (Figure 3f). In other words, a neonatal RBC would need only $75 \%$ of the pressure load for an adult type RBC to obtain the same deformative membrane tension.
RBC filterability data are shown in Figure 4. RBCiv fell significantly $(p<0.001)$ between 1 and $10 \mathrm{~d}$ of age, whereas the filter clogging particles decreased more gradually $(p<0.001$ between $\mathrm{d} 1$ and 70 ). The apparent increase in clogging particles between 70 and $100 \mathrm{~d}$ of age reflects a new lot of Nuclepore filters, (see Materials and Methods).

\section{DISCUSSION}

Our data on neonatal rat $\mathrm{RBC}$ are, in principle, in agreement with previous reports on human neonates. The most obvious difference is that the variations in most RBC parameters between neonatal and adult $\mathrm{RBC}$ are more pronounced in rats than in humans. Thus, the mean RBC vol was about 2.5 times more in neonatal than in adult rats, but about 1.2 times greater for human $\operatorname{RBCs}(4,23)$.

The concentration of $\mathrm{RBC}$ and $\mathrm{Hb}$ in whole blood is reflected 
a)

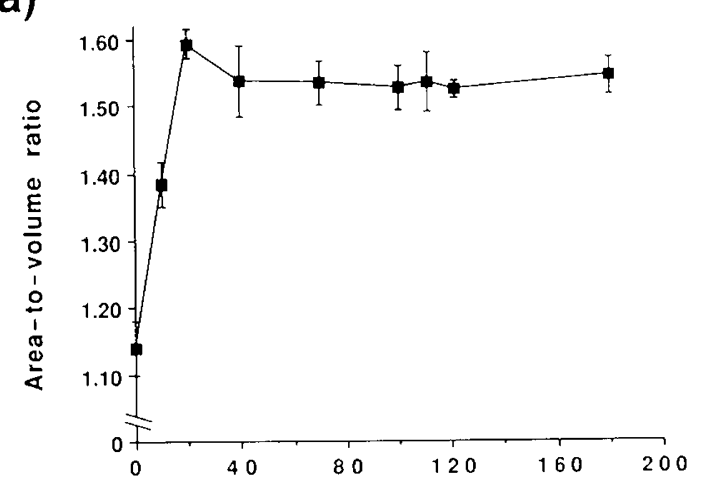

c)

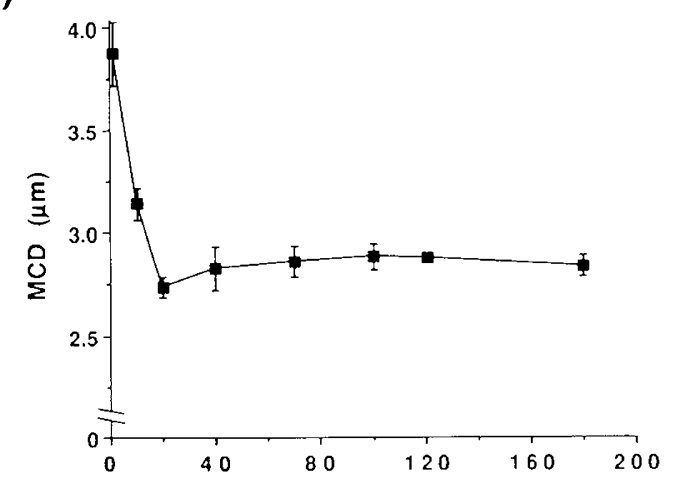

e)

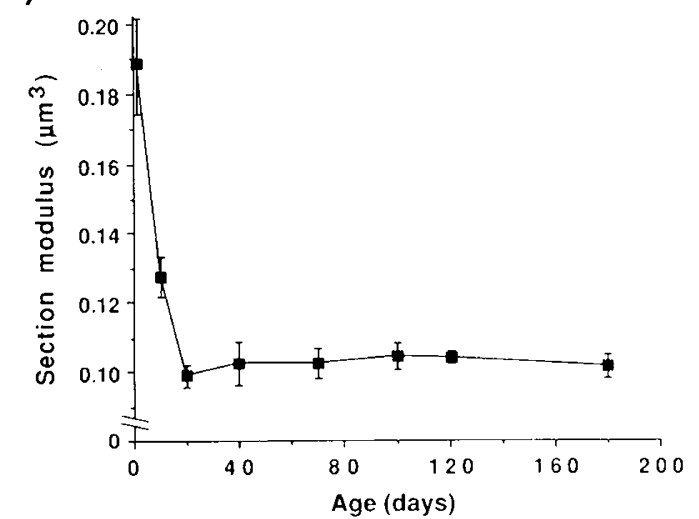

b)

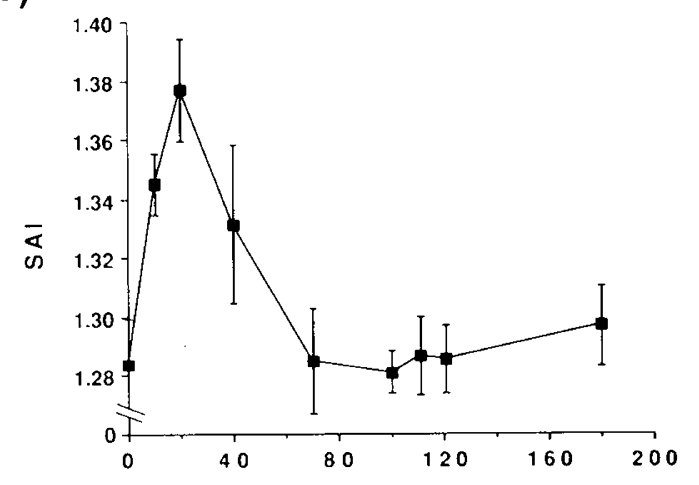

d)

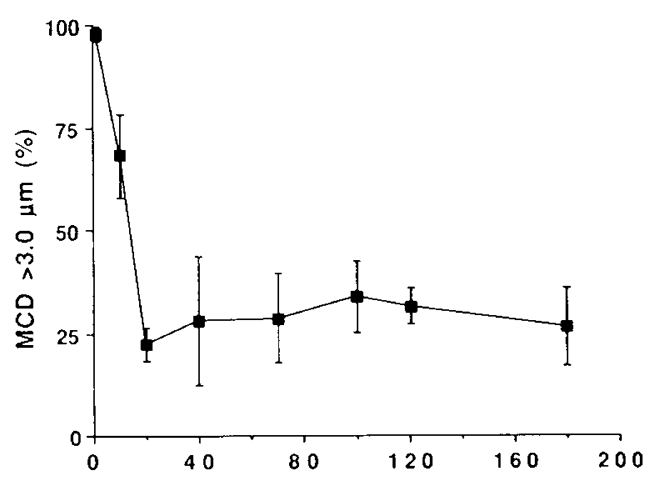

f)

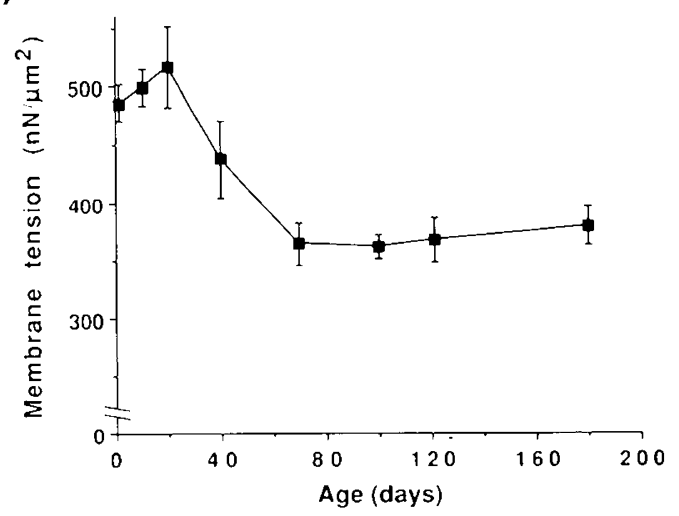

Fig. 3. Calculated $a$, area-to-volume ratio; $b, \mathrm{SAI} ; c, \mathrm{MCD} ; d$, proportion of $\mathrm{RBC}$ exceeding $3 \mu \mathrm{m}$ in $\mathrm{MCD}$; $e$, corpuscle section modulus (high section modulus indicates large resistance to whole cell folding); and $f$, membrane tension induced by a certain pressure load (high membrane tension indicates low resistance to membrane deformation) on the RBC as a function of age. Mean \pm SD in three groups of six rats each (1-20, 4070 , and $100-180 \mathrm{~d}$ of age).

by the MCV, RBC particle concentration, and MCHC. Hematocrit and $\mathrm{Hb}$ decreased to a minimum around $20 \mathrm{~d}$ of age, probably owing to a sequestration of macrocytic neonatal RBC and the insufficient replacement of adult type, smaller $\mathrm{RBC}$. However, the expansion of the vascular volume during growth is also to be considered. An approximate extrapolation of the almost linear fall in hematocrit and $\mathrm{Hb}$ would indicate a depletion of neonatal RBC within about $45 \mathrm{~d}$, which is below the average life span of adult rat RBC, thought to be about $60 \mathrm{~d}$ (24). The life span for human neonatal RBC is 60 to $80 \mathrm{~d}$ as compared to $120 \mathrm{~d}$ for adult $\mathrm{RBC}(25)$.

The RBC size decreased substantially as the rat became adult. However, from a minimum at around $20 \mathrm{~d}$ of age the central thickness reached a new maximum at $100 \mathrm{~d}$, although significantly below the level seen in the 1-d-old rats. In contrast to human neonates $(10,11)$, RBC maximum thickness (toroidal thickness) was markedly greater in neonatal than in adult rat $\mathrm{RBC}$. In the present study, observing RBC cross-sectional profiles, direct thickness measurements were made instead of approximations calculated from RBC vol and diameter (see Ref. 11 , equation 3), and these may therefore be more accurate.

The MCD decreased steeply during the first $20 \mathrm{~d}$ of age. MCD reflects the final deformation into a tube-shaped $\mathrm{RBC}$ and is of interest because it gives an estimate of the ability of the RBC to pass narrow pores, e.g. in the microcirculation or in a filtration test. Therefore, the proportion of RBCs exceeding $3 \mu \mathrm{m}$ in MCD (i.e. the nominal pore size of the Nuclepore membranes used for filtration) was also calculated. Close to $100 \%$ of the neonatal $\mathrm{RBC}$ would apparently plug the pores of the filter, a figure that diminishes to about $25-30 \%$ in adult rats. However, the SAI and SWI indicate a maximum membrane excess for rats of $20 \mathrm{~d}$ of age, whereas neonatal and adult rats are identical from this point 
a)

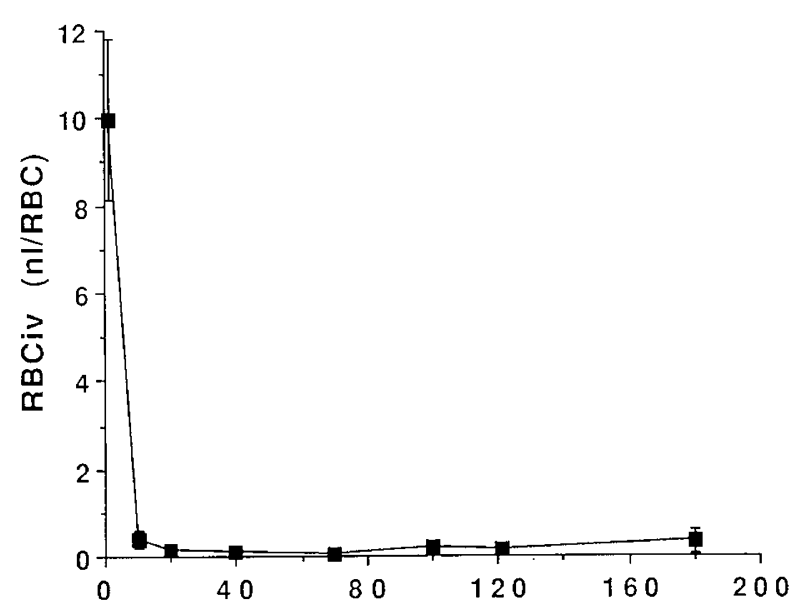

b)

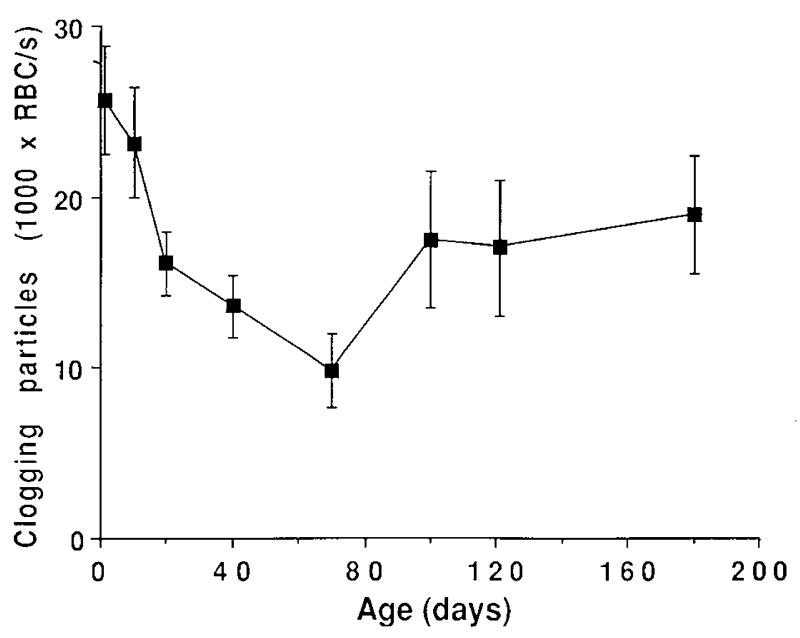

Fig. 4. $a, \mathrm{RBC}$ incremental volume (RBCiv, high RBCiv indicates increased resistance to filtration) and $b$, filter clogging particles as a function of age. The apparent increase in clogging particles between 70 and $100 \mathrm{~d}$ of age reflects a new lot of Nuclepore filters, also seen for $\mathrm{RBCiv}$, although more vaguely (see Materials and Methods). Mean \pm $\mathrm{SD}$ in three groups of 6 rats each (1-20, 40-70, and 100-180 d of age).

of view. This similarity between neonatal and adult RBC has been demonstrated for human neonates as well (10). The exact interpretation of these geometric indices in terms of RBC deformation is not clear-cut, but they may give a hint as to the general $\mathrm{RBC}$ deformability because of the basic need for excess membrane area (10).

The present morphologic method not only gives the correct thickness measurements on RBC cross-sectional profiles but also allows further calculations of RBC deformability as predicted by a static bending analysis of initial folding (15-18). The resistance to fold a neonatal corpuscle was almost twice that for an adult $\mathrm{RBC}$. Interestingly when the projected cell area (the area on which the deformative pressure is loaded) and the distance between points of support during deformation are considered, the membrane tension induced by a given pressure load became significantly greater in neonatal than in adult RBC. Consequently, neonatal RBC may be more easily folded during the initial step of deformation than adult type RBC. This finding may help in explaining the discrepancy between filterability methods and other rheological approaches used to measure neonatal RBC deformability. Under shear forces in a rheoscope the projected area of the RBC must be assumed to play an important role for the cell deformation. At present, the static bending model seems to be the only method that incorporates $\mathrm{RBC}$ diameter in the calculations of deformability.

The analysis of RBC filterability clearly indicated a lower deformability of neonatal RBC, both in terms of RBCiv and filter clogging particles. In addition to RBC shape, RBCiv is sensitive to the viscosity of the cytoplasm and/or the membrane. Inasmuch as the MCHC did not vary notably between neonatal and adult $\mathrm{RBC}$, differences in $\mathrm{Hb}$ viscosity probably do not contribute to the diminished filterability of neonatal RBC. Fetal $\mathrm{Hb}$ does not seem to alter intracellular viscosity (1). Membrane mechanical properties are also unlikely to explain any differences in deformability, because membrane lipid composition is essentially the same for neonatal and adult RBC (26), as are lipid viscosity (12) and membrane elastic moduli (11).

The clogging particles more specifically reflect $\mathrm{RBC}$ shape and their tendency to plug the filter pores. The flow of RBC suspensions in the 1-d-old rat almost stopped after an average of 0.3 $\mathrm{mL}$. The number of suspended RBC contained in this volume corresponds closely to the number of pores of the membrane, indicating almost total plugging. Inasmuch as close to $100 \%$ of neonatal RBC have an MCD above $3.0 \mu \mathrm{m}$, it must be concluded that rigid and large RBC clog the filter pores and not contaminating nucleated cells, as is often claimed (27). Nucleated cells are also largely eliminated during the preparation of the $\mathrm{RBC}$ suspension (19). Furthermore, in a standard experiment only about $15 \mathrm{RBC}$ will pass each filter pore, which makes the occurrence of nucleated $\mathrm{RBC}$ in the 1 -d-old rats, $0.05 \%$, and contaminating $\mathrm{WBC}, 0.002 \%$, unlikely. $\mathrm{RBCiv}$ is not sensitive to nucleated cells either, because being a derivative of the initial $\mathrm{RBC}$ filtration rate is not affected by plugging cells of any sort.

Calculations indicate a maximum RBC deformability already at $20 \mathrm{~d}$ of age in terms of low MCD and section modulus, and high SAI, SWI, and membrane tension (Fig. 3). As suggested by the changes of hematocrit and $\mathrm{Hb}$, it is likely that rigid neonatal $\mathrm{RBC}$ are sequestered at that time, and a pool of young, newly formed and highly deformable, adult type RBC occurs in the circulation. The aging of these adult type $R B C$ is then observed in terms of a diminishing RBC diameter, membrane area, and volume, and an increasing central thickness (Fig. 2). These alterations are well-known attributes for aging of normal RBC (15), but should not be confused with differences between neonatal and adult RBC.

Our study shows that neonatal rat $\mathrm{RBC}$ are more resistant to pore transit, most likely because of their greater size. The impaired filterability through narrow pores may contribute to the shorter life span of neonatal $\mathrm{RBC}$ and to rheologic dysfunctions in newborns. However, a static bending analysis of initial deformation emphasizes that the neonatal RBC are not necessarily less deformable than those of adults, if their greater projected area is taken into consideration. This finding may explain the reported discrepancies between $\mathrm{RBC}$ filtration methods, on the one hand, and viscometry, rheoscopic, or ektacytometric approaches, on the other, in evaluating the deformability of neonatal RBC.

\section{REFERENCES}

1. Reinhart WH, Danoff SJ, King RG, Chien S 1985 Rheology of fetal and maternal blood. Pediatr Res 19:147-153

2. Linderkamp O, Hammer BJ, Miller R 1986 Filterability of erythrocytes and whole blood in preterm and full-term neonates and adults. Pediatr Res 20:1269-1273

3. Pearson HA 1967 Life-span of the fetal red blood cell. J Pediatr 70:166-171

4. Linderkamp O, Güntner M, Hiltl W, Vargas VM 1986 Erythrocyte deformability in the fetus, preterm, and term neonate. Pediatr Res 20:93-96

5. Gatti RA, Muster AJ, Cole RB, Paul MH 1966 Neonatal polycythemia with transient cyanosis and cardio-respiratory abnormalities. J Pediatr 69:10631072

6. Mentzer WC 1978 Polcythemia and the hyperviscosity syndrome in newborn infants. Clin Haematol 7:63-74

7. Black VD, Lubchenco LO 1982 Neonatal polycythaemia and hyperviscosity. Pediatr Clin North Am 29:1137-1148

8. Rosenkrantz TS, Oh W 1982 Cerebral blood flow velocity in infants with 
polycythemia and hyperviscosity: effects of partial exchange transfusion with plasmanate. J Pediatr 101:94-98

9. Hakanson DO, Oh W 1977 Necrotizing enterocolitis and hyperviscosity in the newborn infant. J Pediatr 90:458-46

10. Linderkamp O, Wu PYK, Meiselman HJ 1983 Geometry of neonatal and adult red blood cells. Pediatr Res 17:250-253

11. Linderkamp O, Nash GB, Wu PYK, Meiselman HJ 1986 Deformability and intrinsic material properties of neonatal red blood cells. Blood 67:1244-1250

12. Crespo LM, Bifano EM, Freedman JC 1988 Membrane lipid fluidity and filterability of red blood cells from adults and newborns. Pediatr Res 24:433437

13. Coulombel L, Tchernia G, Feo C, Mohandas N 1982 Echinocytic sensitivity and deformability of human newborn red cells. Biol Neonate 42:284-290

14. Canham PB, Potter RF, Woo D 1984 Geometric accommodation between the dimensions of erythrocytes and the calibre of heart and muscle capillaries in the rat. J Physiol 347:697-712

15. Engström G, Täljedal I-B 1985 Effects of shape and size on red blood cel deformability: a static bending analysis. Acta Physiol Scand 125:669-679

16. Engström KG, Täljedal I-B 1987 Altered shape and size of red blood cells in obese hyperglycaemic mice. Acta Physiol Scand 130:535-543

17. Engström KG, Täljedal I-B 1988 Increased size and biconcavity in red blood cells of obese-hyperglycaemic mice. Biorheology 25:625-638
18. Engström KG 1989 Mechanics of the red blood cell corpuscle: section modulus, shape and stringent profile-curvature equation. J Theor Biol 138:529-544

19. Engström KG 1989 A new red blood cell filtration device with improved time resolution and its application to the impaired RBC deformability in the diabetic $o b / o b$ mouse. Biorheology 26:711-721

20. Korpman RA, Dorrough DC, Brailsford JD, Bull BS 1977 The red cell shape as an indicator of membrane structure. Blood Cells 3:315-334

21. Evans EA, LaCelle PL 1975 Intrinsic material properties of the erythrocyte membrane indicated by mechanical analysis of deformation. Blood 45:2943

22. Matrai A, Reid H, Bogar L, Flute PT, Dormandy JA 1985 Initial filtration rate and initial clogging in the hemorheometre. Biorheology 22:275-284

23. Matovcik LM, Chiu D, Lubin B, Mentzer WC, Lane PA, Mohandas N, Schrier SL 1986 The aging process of human neonatal erythrocytes. Pediatr Res 20:1091-1096

24. Van Putten LM 1958 The life span of red cells in the rat and the mouse as determined by labeling with DFP ${ }^{32}$ in vivo. Blood 13:789-794

25. Bratteby L-E Garby L, Groth T Schneider W, Wadman B 1968 Studies on erythro-kinetics in infancy. XII The mean life span and the life span frequency function of red blood cells formed during foetal life. Acta Paediatr Scand 57:311-320

26. Neerhout RC 1968 Erythrocyte lipids in the neonate. Pediatr Res 2:172-178

27. Chien S, Schmalzer EA, Lee MML, Impelluso T, Skalak R 1983 Role of white blood cells in filtration of blood cell suspensions. Biorheology 20:11-27 